\title{
FENOLOGIA DE DUAS ESPÉCIES DE IPÊ EM ÁREA URBANA DO MUNICÍPIO DE ARARAS, SÃO PAULO, BRASIL
}

\author{
Daniele Rebelatto $^{12}$; Thiago Souza Leal ${ }^{1}$; Cristiano Pedroso de Moraes ${ }^{3}$
}

\section{RESUMO}

A fenologia visa reunir informações sobre o estabelecimento das espécies em um local, podendo ser alterada pelo ambiente e microclima urbanos. O presente trabalho objetivou analisar a influencia do ambiente urbano sobre a fenologia de Tabebuia chrysotricha e Tabebuia impetiginosa. Foram selecionados 100 indivíduos de cada espécie presentes em duas avenidas movimentadas de Araras, SP, para os quais foi realizado monitoramento mensal das fenofases: queda foliar, brotamento, floração, frutificação e deiscência, de maio/2010 a abril/2011. As variáveis climáticas: temperatura, precipitação, velocidade do vento e fotoperíodo foram obtidas pela consulta à base do CEPAGRI. Os picos de queda foliar coincidiram com os de maior estresse hídrico, enquanto o brotamento teve picos em meses com maior precipitação, incidência solar e temperatura. Verificou-se que nem todos os indivíduos floresceram, sendo que para T. chrysotricha esta fenofase estendeu-se de agosto a setembro, diferindo do encontrado em ambiente natural, enquanto T. impetiginosa floresceu de maio a agosto, tal como ocorre na natureza. A frutificação foi baixa para ambas as espécies e a dispersão ocorreu de agosto a novembro, meses em que a velocidade do vento foi maior. Constatou-se que o clima urbano pode influenciar na fenologia das espécies estudadas, principalmente a floração e a frutificação.

Palavras-chave: Arborização urbana; Clima urbano; Padrão fenológico; Tabebuia.

\section{PHENOLOGY OF TWO IPÊ SPECIES IN URBAN AREA OF ARARAS CITY, SÃO PAULO, BRAZIL}

\begin{abstract}
The present study aimed to analyze the influence of the urban environment on the phenology of Tabebuia chrysotricha and Tabebuia impetiginosa. There were selected 100 individuals of each species in two busy avenues in Araras, SP, for which there conducted monthly monitoring for the phenophases: leaf fall, budding, flowering, fructification and dehiscence, from May 2010 to April 2011. The climate data: temperature, precipitation, wind velocity and photoperiod were obtained by consulting to CEPAGRI database. The peak leaf fall coincided with the highest water stress, while the budding had its peaks during the months with higher rainfall, solar incidence and temperature. There were verified that not all individuals flourished, and that $T$. chrysotricha this phenophase was extended from August to September, differing from those found in natural environment, while T. impetiginosa flowered from May to August, as occurs in nature. The fructification was low for both species and the dispersion occurred from August to November, months when the wind velocity was higher. It was found that the urban climate can influence the phenology of the species, especially flowering and fruiting.
\end{abstract}

Key-words: Urban forestry; Urban climate; Phenological pattern; Tabebuia.

\footnotetext{
${ }^{1}$ Alunos de Iniciação Científica do Centro Universitário Hermínio Ometto - Uniararas. Av. Maximiliano Baruto, 500.

${ }^{2}$ recebido em 23.04.2012 e aceito para publicação em 15.03.2013

${ }^{3}$ Pós-Doutorando do Departamento de Biologia. Universidade de Aveiro, CEP: 3810-193, Aveiro, AV., Portugal. Docente do Centro

Universitário Hermínio Ometto - Uniararas. Rua Maximiliano Baruto, 500, Jd. Universitário. 13607-330. Araras, SP. pedroso@uniararas.br
}

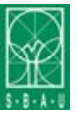


Fenologia é o estudo dos aspectos biológicos que se sucedem no desenvolvimento de uma espécie, acomodados dentro de certo ritmo periódico como brotação, floração e maturação de frutos (LONGHI,1984; BRUN, 2007). Entre os diferentes fatores que condicionam os padrões fenológicos das espécies vegetais, a sazonalidade climática provavelmente seja o mais importante. Além do clima regional, as plantas estão sujeitas às variações ambientais locais que podem ter influência no comportamento fenológico (MARQUES; OLIVEIRA, 2004; PALIOTO et al., 2007).

Tais estudos contribuem para o entendimento da regeneração e reprodução das plantas, da organização temporal dos recursos dentro das comunidades, das interações planta-animal e da evolução da história de vida dos animais que dependem de plantas para alimentação, como herbívoros, polinizadores e dispersores (MORELATTO; LEITÃO FILHO, 1990; 1996; ROSSATO, 2008). Dessa forma, observações fenológicas obtidas de forma sistemática reúnem informações sobre o estabelecimento de espécies, que podem estar associadas a mudanças na qualidade e abundância de recursos, como luz e água (MORELATTO, 1990; ALMEIDA; ALVES, 2000).

$\mathrm{Na}$ arborização urbana, as plantas ornamentais são largamente utilizadas, pois, distinguem-se pelo florescimento, pela forma ou colorido das folhas e pela forma e aspecto geral das plantas (LORENZI; SOUZA, 2001). O conhecimento fenológico das espécies vegetais componentes, que sempre vivem sob algum nível de estresse fisiológico, pode indicar, de acordo com o seu ritmo de suas fenofases em situação natural, a presença ou ausência de regularidade no mesmo e, neste último caso, ser base para o planejamento de ações silviculturais que permitam melhor adaptação das espécies ao ambiente urbano (LONGHI, 1984; BRUN, 2007).

Dentre as famílias botânicas mais utilizadas em arborização urbana, destaca-se Bignoniaceae Juss. Esta possui distribuição pantropical e apresenta cerca de 120 gêneros e 800 espécies. No Brasil são registrados aproximadamente 50 gêneros e 350 espécies (SOUZA; LORENZI, 2008). São plantas lenhosas, predominantemente de hábito lianescente, com folhas opostas compostas com folíolos, frequentemente modificado em gavinhas. Suas flores são tubulosas, bilabiadas, monoclinas, oligostêmones com estames epipétalos, didínamos, com estaminódio geralmente presente, gineceu bicarpelar, ovário súpero, estilete bífido, fruto cápsula e sementes aladas (BARROSO et al., 1991).

O gênero Tabebuia é o mais comum dentro desta família, e inclui os Ipês (SOUZA; LORENZI, 2008). Estas árvores são consideradas ótimas para o paisagismo tanto pela folhagem densa de cor verdeazulada e forma piramidal da copa, quanto por suas flores, que podem ocorrer mais de uma vez ao ano (LORENZI, 2002).

Devido aos fatores supracitados e corroborando com as afirmações de Potascheff e Morelatto (2007), de que a fenologia mostra-se como uma importante ferramenta para o entendimento da inferência de alterações microclimáticas em áreas urbanas, o presente trabalho teve por objetivo realizar o monitoramento fenológico de Tabebuia chrysotricha (Mart. ex DC.) Standl. e Tabebuia impetiginosa (Mart.) Standl. analisando suas fenofases a fim de Daniele Rebelatto et al..

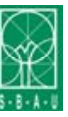


verificar se as variações climáticas estão alterando seu ciclo de vida na área urbana do município de Araras,
SP.

\section{MATERIAL E MÉTODOS}

\section{Caracterização morfoecológica das espécies}

Tabebuia chrysotricha, conhecida como ipê-amarelocascudo é encontrado em Floresta Ombrófila Densa e em áreas de matas de galeria no domínio do Cerrado, sendo mais frequente nas formações secundárias localizada sobre solos bem drenados de encostas. É uma planta heliófita decídua com alto valor ornamental, extremamente utilizada para arborização em praças e ruas, devido ao seu pequeno porte, sendo considerada uma das árvores-símbolo do país (MENDONÇA et al., 1998; KAGEYAMA et al., 2001; LORENZI, 2002). Apresentam folhas palmadas penta-folioladas, com folíolos elíptico-oblongos ásperos, coriáceos, pubescentes em ambas as faces, sendo o terminal maior, com até $11 \mathrm{~cm}$ de comprimento. Floresce durante os meses de agosto e setembro, geralmente com a planta totalmente despida de folhagem. A inflorescência é tirsóide ou fasciculada muito curta, com 8-10 flores surgindo em ramos afilos, com lenho velho. As flores são de cor amarelo ouro e campanuladas, medindo de $6-7 \mathrm{~cm}$ de comprimento. Os frutos caracterizam-se como cápsulas deiscentes medindo de 11-38 cm de comprimento e 0,8-2 cm de largura, de cor ocrácea; as valvas são densamente ferrugíneo-tomentosas com pelos ramosos e glabrescentes com a idade. Amadurecem a partir do final de setembro a meados de outubro. Sua dispersão é descontínua e irregular, geralmente ocorrendo em baixa frequência, mesmo

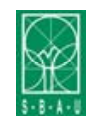

Soc. Bras. de Arborização Urbana com a espécie produzindo anualmente grande quantidade de sementes (LORENZI, 2002; CARVALHO, 2006b).

Tabebuia impetiginosa, conhecida vulgarmente como ipê-rosa, ipê-preto, ipê-rosa-de-folha-larga, ipêrosado, ipê-roxo-da-casca-lisa, ipeúna, ipê-de-minas e pau-d'arco ocorre em áreas de Floresta Estacional Semidecidual Submontana, Floresta Ombrófila Densa, Floresta Estacional Decidual, no domínio do Cerrado, Caatinga e Pantanal (LORENZI, 2002; CARVALHO, 2006a). Caracteriza-se como uma espécie caducifólia, que atinge até $15 \mathrm{~m}$ de altura e 30 $\mathrm{cm}$ de diâmetro à altura do peito (DAP). Suas folhas são compostas, com folíolos coriáceos, pubescentes em ambas as faces e levemente serreados até o ápice (CARVALHO, 1994). Floresce, geralmente, durante os meses de maio-agosto com a árvore totalmente despida da folhagem, sendo o amadurecimento dos frutos processado em meados de setembro até outubro (LORENZI, 2002). Suas flores são grandes, de forma tubular, sua corola é frequentemente rosa ou magenta apresentando quatro estames e um estaminódio. Seus frutos consistem em cápsulas deiscentes alongados contendo inúmeras sementes aladas (BAZAMENDONÇA; ANJOS, 2005).

\section{Área de estudo}

O trabalho foi desenvolvido mensalmente no período de maio de 2010 a abril de 2011, com 100 indivíduos FENOLOGIA DE DUAS ESPÉCIES DE IPÊ... 
de cada espécie, presentes nos canteiros centrais das avenidas Goffredo Teixeira da Silva Telles

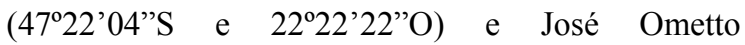
(47²2’28”S e 22²2’21”O), município de Araras, SP. Tais avenidas são asfaltadas, bem movimentadas e possuem construções ao redor, os canteiros possuem 1 metro de largura e a distância entre as árvores varia de 2-3 metros.
O clima da área corresponde, segundo a classificação de Köeppen, ao tipo Cwa, isto é, clima temperado úmido, com inverno seco e verão quente com temperaturas $\geq 22^{\circ} \mathrm{C}$. O total das chuvas no mês mais seco não ultrapassa $30 \mathrm{~mm}$. A temperatura do mês mais quente oscila entre $22^{\circ} \mathrm{C}$ e $14^{\circ} \mathrm{C}$ (MAGINI; CHAGAS, 2003), dados confirmados pela análise do climograma do município de Araras (Figura 1).

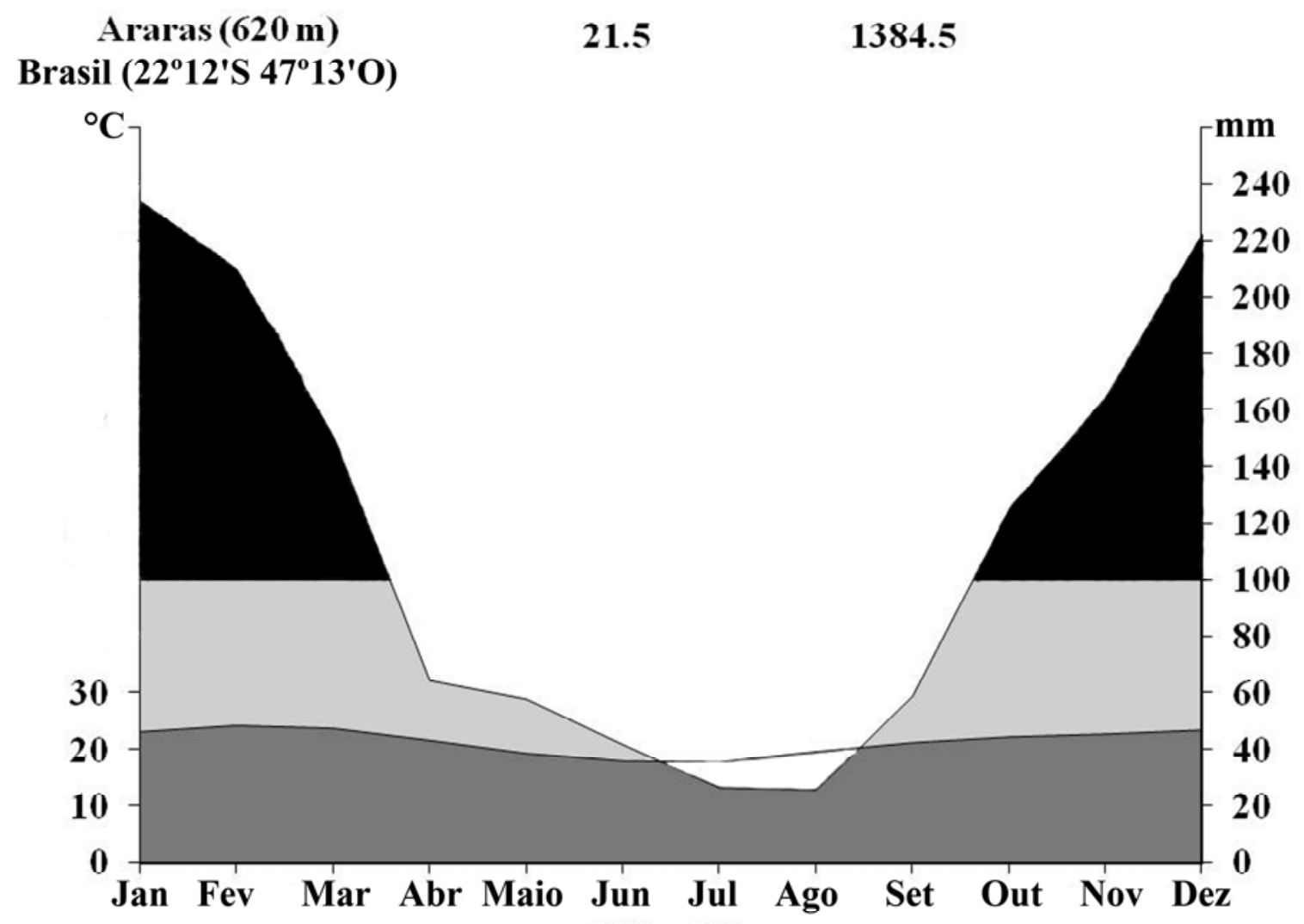

Figura 1. Climograma do município de Araras, interior do Estado de São Paulo (Dados de 30 anos - 1980 a 2010 CEPAGRI). 


\section{Procedimento}

As espécies foram registradas e o material fértil coletado foi herborizado, conforme os procedimentos usuais (MORI et al., 1989). A identificação foi realizada por meio de comparações com espécimes da coleção didática do Centro Universitário Hermínio Ometto - UNIARARAS, onde as exsicatas foram tombadas. Os nomes das espécies foram verificados no Index Kewensis online (2010).

As fenofases foram definidas segundo Morellato et al. (1989), sendo: floração - período em que as árvores apresentam as flores em antese (flores abertas); frutificação - período em que os frutos estão maduros e prontos para serem dispersos; brotamento e queda foliar. As observações ocorreram mensalmente, como recomendado por Frankie et al. (1974) e por Fournier e Charpantier (1975), no período de maio de 2010 a abril de 2011. A intensidade dos eventos fenológicos foi estimada individualmente pelo método de Fournier (1974), obtendo-se o percentual de ocorrência de cada fenofase. As curvas fenológicas foram elaboradas seguindo metodologia adaptada de Morellato et al. (1989). Foram obtidos ainda os dados referentes à fotoperíodo, precipitação, temperatura média e velocidade do vento por meio de consulta à base de dados CEPAGRI (Universidade de Campinas - UNICAMP). Para a avaliação da influência dos fatores abióticos sobre cada fenofase, foram estabelecidas correlações de Pearson $(r)$ com o auxilio do aplicativo estatístico BioEstat 5.3. Para estas avaliações, foram consideradas significativas somente correlações, tanto positivas quanto negativas, que obtiveram coeficiente superior a $30 \%(r>0,30$ ou $r<-0,30)$, sendo considerados baixos aqueles situados entre 30 e $40 \%(0,30<r \leq 0,40$ ou $-0,30>r$ $\geq-0,40)$ e altos, aqueles superiores a $40 \%(r>0,40$ ou $r<-0,40)$ (Adaptado de BRUN et al., 2007).

\section{RESULTADOS E DISCUSSÃO}

A Tabela 1 demonstra as correlações dos fenociclos com os fatores abióticos do meio urbano e a Figura 2, integra tanto os dados climáticos quanto os fenológicos obtidos (Figura 2 A-C), nos quais é possível notar que as fenofases vegetativas ocorreram durante todo ano nas duas espécies (Figura 2-D e E). As fenofases avaliadas são mostradas em indivíduos de T. chrysotricha (Figura 3) e de T. impetiginosa (Figura 4). A fenologia possibilita avaliar características importantes para compreensão do dinamismo que há nas populações e comunidades vegetais, e também, é uma possível indicadora de condições climáticas e edáficas de um ambiente (LENZI; ORTH, 2004), inclusive, o meio urbano.

FENOLOGIA DE DUAS ESPÉCIES DE IPÊ... 
Tabela 1. Correlações de Pearson $(r)$ entre as variáveis climáticas e as fenofases das espécies de Ipê (Tabebuia chrysotricha e Tabebuia impetiginosa)

\begin{tabular}{|c|c|c|c|c|c|}
\hline \multirow{3}{*}{ FENOFASE } & \multirow{3}{*}{$\begin{array}{l}\text { VARIÁVEL } \\
\text { CLIMÁTICA }\end{array}$} & \multicolumn{4}{|c|}{ ESPÉCIES } \\
\hline & & \multicolumn{2}{|c|}{ Tabebuia chrysotricha } & \multicolumn{2}{|c|}{$\underline{\text { Tabebuia impetiginosa }}$} \\
\hline & & $\boldsymbol{R}$ & $p$ & $r$ & $p$ \\
\hline \multirow{4}{*}{ Queda Foliar } & Fotoperíodo & $-0,40$ & 0,19 & $-0,85$ & $0,00 *$ \\
\hline & Precipitação & $-0,54$ & 0,06 & $-0,86$ & $0,00^{*}$ \\
\hline & Temperatura & $-0,55$ & 0,05 & $-0,86$ & $0,00 *$ \\
\hline & Velocidade do Vento & 0,80 & $0,00^{*}$ & 0,48 & 0,10 \\
\hline \multirow{4}{*}{ Brotamento } & Fotoperíodo & 0,39 & 0,20 & 0,30 & 0,34 \\
\hline & Precipitação & 0,41 & 0,17 & 0,10 & 0,74 \\
\hline & Temperatura & 0,31 & 0,31 & 0,03 & 0,91 \\
\hline & Velocidade do Vento & 0,14 & 0,64 & 0,61 & $0,03 * *$ \\
\hline \multirow{4}{*}{ Floração } & Fotoperíodo & $-0,46$ & 0,12 & $-0,96$ & $0,00^{*}$ \\
\hline & Precipitação & $-0,55$ & 0,05 & $-0,89$ & $0,00 *$ \\
\hline & Temperatura & $-0,64$ & $0,02 * *$ & $-0,90$ & $0,00 *$ \\
\hline & Velocidade do Vento & 0,84 & $0,00^{*}$ & 0,16 & 0,59 \\
\hline \multirow{4}{*}{ Frutificação } & Fotoperíodo & 0,02 & 0,94 & $-0,53$ & 0,07 \\
\hline & Precipitação & $-0,16$ & 0,60 & $-0,66$ & $0,01 * *$ \\
\hline & Temperatura & $-0,23$ & 0,46 & $-0,71$ & $0,00^{*}$ \\
\hline & Velocidade do Vento & 0,83 & $0,00^{*}$ & 0,82 & $0,00^{*}$ \\
\hline \multirow{4}{*}{ Deiscência } & Fotoperíodo & 0,24 & 0,44 & $-0,11$ & 0,71 \\
\hline & Precipitação & 0,01 & 0,96 & $-0,28$ & 0,37 \\
\hline & Temperatura & $-0,03$ & 0,90 & $-0,31$ & 0,32 \\
\hline & Velocidade do Vento & 0,87 & $0,00 *$ & 0,86 & $0,00^{*}$ \\
\hline
\end{tabular}

* Significativo a 1\% de probabilidade; ** Significativo a 5\% de probabilidade; $n=12$.

* Significant of $1 \%$ of probability; ** Significant of $5 \%$ of probability; $n=12$. 

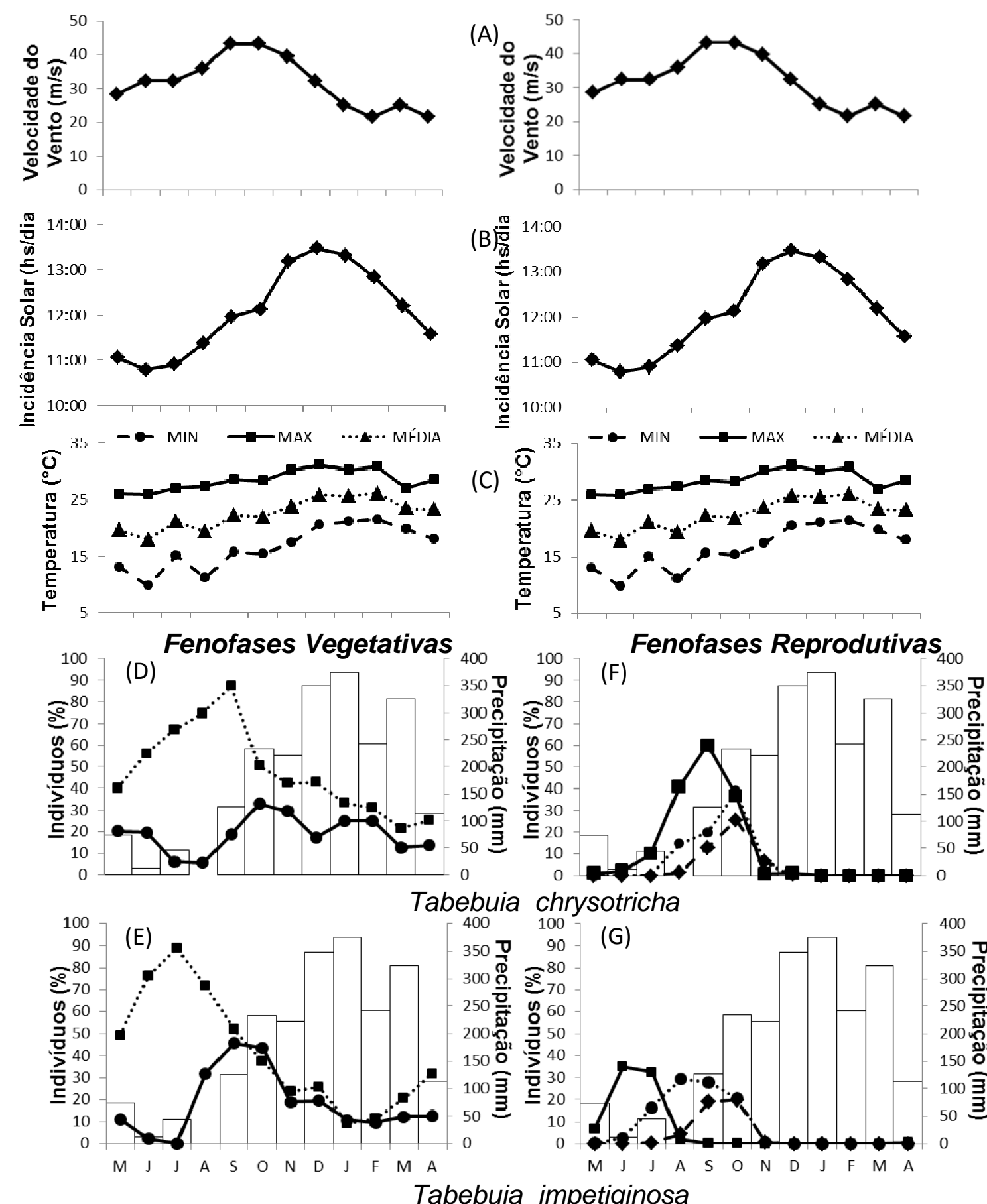

Figura 2. Dados climáticos em (A), (B) e (C) ao longo do período de estudo. Intensidade de Fournier das fenofases Vegetativas e Reprodutivas sendo, respectivamente, (D) e (F) de Tabebuia chrysotricha e (E) e (G) de Tabebuia impetiginosa $\cdots \cdot$ Queda Foliar, - Floração, $\cdots \cdot \cdots$ Frutificação e $-\bullet-$ Deiscência.

FENOLOGIA DE DUAS ESPÉCIES DE IPÊ... 



Figura 3. Fenofases vegetativas e reprodutivas de Tabebuia chrysotricha situadas na área urbana de Araras, SP. Em A, queda foliar. B, brotamento. C, floração (quadro menor, detalhe da inflorescência). D, frutificação e deiscência (quadro menor, detalhe de frutos imaturos).

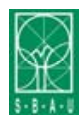



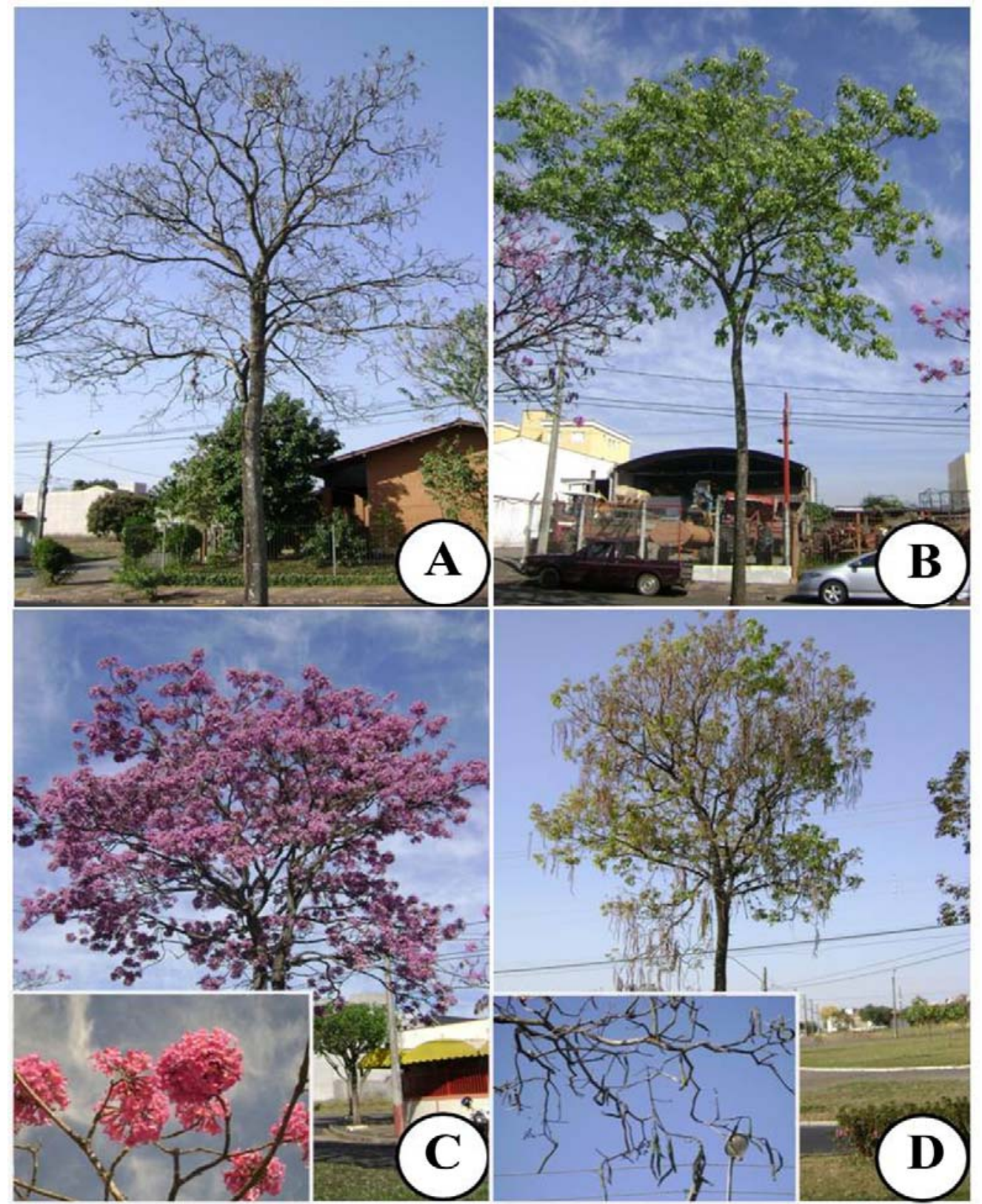

Figura 4. Fenofases vegetativas e reprodutivas de Tabebuia impetiginosa situadas na área urbana de Araras, SP.

Em A, queda foliar. B, brotamento. C, floração (quadro menor, detalhe da inflorescência). D, frutificação e deiscência (quadro menor, detalhe de frutos imaturos).

A queda foliar se processou ao longo de todo ano para ambas as espécies, variando entre 11 e $89 \%$. Observou-se que, coincidentemente com a maior

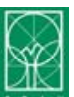

precipitação (outubro de 2010 a março de 2011) a queda foliar foi menor que em outros meses (maio a setembro 2010), sendo que os picos ocorreram nos

FENOLOGIA DE DUAS ESPÉCIES DE IPÊ... 
meses de maior estresse hídrico (junho a setembro de 2010). Tal fato é confirmado por Pereira e Amaral (2008) em estudos com espécies arbóreas, dentre elas T. chrysotricha, em um bosque de Patos de Minas MG, no qual foi observado que para a espécie, a queda foliar se relacionou com o período de menores índices pluviométricos e o de transição para a estação úmida, o que também confirma os resultados obtidos para $T$. impetiginosa. Houve forte correlação positiva entre a fenofase queda foliar e velocidade do vento $(r=0,8)$ para T. chrysotricha (Tabela 1), o que pode ser atribuído, em parte, à ação mecânica do vento, a qual permite o rompimento prematuro das zonas de abscisão foliares e, também, ao estresse hídrico imposto à população analisada, relacionados a seu estabelecimento em canteiros de pequenas dimensões, os quais, por sua vez são lateralmente impermeabilizados pela cobertura asfáltica. Tais constatações são alicerçadas no fato de que a diminuição da quantidade de água nas camadas mais superficiais do solo, no início da estação seca, tem sido associada com a queda foliar devido ao declínio do potencial hídrico, o qual induziria essa fenofase (CORLETT, 1993). Ainda, para T. impetiginosa, com relação à fenofase velocidade do vento, foram encontradas fortes correlações negativas para 0 fotoperíodo $(r=-0,85)$, precipitação e temperatura média $(r=-0,86)$ (Tabela 1). Tais resultados são devidos ao fato de que no início da estação seca, ocorre aumento da insolação, temperatura e diminuição da precipitação. O aumento da evapotranspiração, associado à ação mais efetiva dos ventos, está associado à maior retirada de nutrientes do solo, sendo que ao final dessa estação a absorção de nutrientes é dificultada pela baixa umidade do ar e a diminuição da disponibilidade de água no solo, ocasionando assim, a perda das folhas da maioria das espécies (MORELLATO, 1992; GUILHERME et al., 2011).

A produção de folhas ocorreu em baixa intensidade no período analisado, variando entre 0 a $46 \%$, sendo que os maiores picos ocorreram no final da estação seca e início da chuvosa em ambas as espécies (Figura 2-D e E). Em T. chrysotricha nos meses de julho e agosto e em T. impetiginosa em junho e julho, a porcentagem dos indivíduos para brotação foi abaixo de $10 \%$, sendo tal fato devido ao curto período de incidência solar (Figura 2-B) e o início do aumento da velocidade dos ventos, o que originou forte correlação negativa $(r=-0,61)$ para este fator abiótico e a fenofase em T. impetiginosa. Segundo Brun et al. (2007), tal fato pode ter inibido a ação dos hormônios responsáveis pela formação de tecidos foliares e conseqüentemente inibindo a formação dos brotos neste período. Nota-se também, que conforme constatado por Amorim et al. (2009) a formação de folhas é influenciada pela pluviosidade em $T$. impetiginosa. Considerando os resultados obtidos e observações realizadas por Morelatto et al. (2000) de que indivíduos arbóreos apresentaram picos de brotamento em meses mais quentes e úmidos, pode-se concluir que o aumento na disponibilidade de água, e temperatura e o declínio da insolação, induziram o brotamento das espécies.

A floração em T. impetiginosa iniciou-se em meados de maio (Figura 2-G), atingindo o máximo da atividade em junho com $35 \%$ dos indivíduos e em $T$. chrysotricha (Figura 2-F) iniciou-se em julho, sendo mais pronunciada em setembro $(60 \%)$, períodos estes em que a temperatura apresentou os menores valores e forte correlação negativa para ambas as espécies, tal como a precipitação e a insolação, as quais correlacionaram-se forte e negativamente com $T$.

Daniele Rebelatto et al.. 
impetiginosa (Figura 2-C e F; Tabela 1). Também se pôde observar forte correlação positiva em relação à velocidade do vento para T. chrysotricha (Tabela 1).

Segundo Lorenzi (2002), T. chrysotricha em ambientes naturais, floresce nos meses de agosto a setembro, e Martini et al. (2011) encontraram períodos condizentes ao natural em exemplares da espécie em canteiros urbanos de Curitiba-PR. Já os resultados para floração obtidos, divergiram dos descritos para o meio natural, mas, praticamente coincidiram com os encontrados por Palioto et al. (2007), em estudos feitos no Campus da Universidade Estadual de Maringá, na qual a fenofase foi de julho (estação fria e seca) à setembro. Entretanto, no presente trabalho, a floração estendeu-se a outubro, mês do qual a precipitação apresentou-se elevada.

A floração em T. impetiginosa não foi observada em todos os indivíduos acompanhados, assim como verificado também por Amorim et al. (2009) em estudos feitos na caatinga de Seridó-RN. Porém, os poucos que floresceram, coincidiram com os dados levantados por Lorenzi (2002), ou seja, ocorrência entre maio e agosto.

De acordo com inúmeros pesquisadores (RODRIGUES; SHEPHERD, 2000; WILLIAMSLINERA; MEAVE, 2002; COELHO; MACHADO, 2009), a floração em espécies do cerrado está diretamente relacionada ao aumento da temperatura, à diminuição da precipitação, dias mais curtos e ao aumento da evapotranspiração relacionada a maiores velocidades do vento, pois o declínio da umidade ambiental e do fotoperíodo, induzem o início da floração de espécies em florestas secas (RIVERA; BORCHERT, 2000; COELHO; MACHADO, 2009), o que explica a forte correlação negativa encontrada entre este fenociclo e os fatores abióticos fotoperíodo,

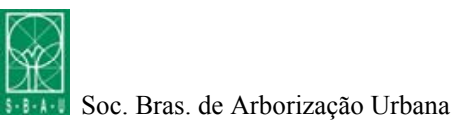

precipitação e temperatura média para $T$. impetiginosa e correlação fortemente positiva para velocidade do vento em $T$. chrysotricha.

Todos os indivíduos que floresceram, frutificaram, porém esta fenofase ocorreu com baixa intensidade, sendo o maior pico de $T$. chrysotricha de $38 \%$ e de $T$. impetiginosa de 30\%. No ipê-amarelo, a emissão dos frutos iniciou-se em agosto, teve seu pico em outubro e fora quase nulo em novembro, enquanto o ipê-rosa frutificou de junho a outubro. Quanto à maturação dos frutos, ambas as espécies corroboraram com os resultados obtidos por Lorenzi (2002), que afirma que este período se dá entre setembro e outubro.

$\mathrm{O}$ fato de nem todos os indivíduos terem florescido e a ocorrência de baixa frutificação, podem estar relacionados às condições do local de estabelecimento, pois além das características intrínsecas das espécies, as variações climáticas também influenciam a fenologia (FERRAZ et al., 1999). Tal fato é corroborado com o estresse hídrico e térmico que $T$. impetiginosa sofre em tais locais, evidenciado pela forte correlação negativa encontrada para tais variáveis abióticas em relação à frutificação (Tabela 1).

Para ambas as espécies foram encontradas fortes correlações positivas para a variável velocidade do vento (Tabela 1), o que pode estar relacionado ao fato de que há um ajustamento das fenofases para garantir que a dispersão, principalmente das sementes que não apresentam dormência, ocorra em um período favorável à sua germinação, que coincide com o início do período chuvoso (OLIVEIRA, 2008; SILVÉRIO; LENZA, 2010). Assim, frutos secos e anemocóricos do Cerrado possuem vantagens para dispersão na seca (BATALHA; MANTOVANI, 2000; OLIVEIRA, 2008). Além disso, a ligação FENOLOGIA DE DUAS ESPÉCIES DE IPÊ... 
temporal e funcional entre as distintas fenofases parece ser o fator determinante para o sucesso da germinação e estabelecimento dos novos indivíduos (SILVÉRIO; LENZA, 2010). Entretanto, deve-se levar em consideração que no ambiente urbano há um menor número de polinizadores, o que culmina em menores taxas de frutificação.

As espécies estudadas apresentam sementes pequenas e leves, com estruturas aerodinâmicas que auxiliam o voo, por isso são consideradas anemocóricas, e a deiscência de ambas ocorreu entre os meses de agosto a novembro coincidindo com o pico de velocidade do vento nas áreas estudadas (Figura 2-A). A deiscência se deu com os frutos ainda fixos aos galhos, com exposição das sementes até a completa dispersão dos propágulos. O pico de dispersão das sementes entre agosto e setembro pode ser explicado pela época do ano, caracterizada pela baixa precipitação e umidade, ocorrência de ventos intensos e caracteres filogenéticos associados à família Bignoniaceae (GUILHERME et al., 2011), sendo tal fato corroborado pela correlação obtida entre o fenociclo deiscência e a variável velocidade do vento, que apresentou forte correlação positiva tanto para $T$. chrysotricha $(r=0,87)$ quanto para T. impetiginosa $(r$ $=0,86)($ Tabela 1) e pelas constatações de Morellato (1992) e Schaik et al. (1993) de que a deiscência de frutos ocorre algumas semanas antes do início das chuvas, quando o clima é propício à dispersão de propágulos anemocóricos, proporcionando melhores condições de germinação das sementes e estabelecimento das plântulas nesse período. Além disso, estudos em cerrados (BATALHA; MARTINS, 2004) e em florestas estacionais semi-deciduais (MORELLATO et al., 1989; SANTOS; TAKAKI, 2005) têm mostrado que os padrões fenológicos de espécies arbóreas anemocóricas apresentam frutificação concentrada na estação seca. Assim, cada espécie possui seu período para florescer e frutificar, mas o mesmo não ocorre com a dispersão, que é sazonal. É importante lembrar, que ao iniciar a estação úmida, há um período de melhores condições para a germinação e o crescimento das plântulas (PEREIRA; AMARAL, 2008), por isso os propágulos anemocóricos são dispersos antes deste período.

\section{CONCLUSÕES}

As observações realizadas permitiram determinar a época e a duração das fenofases analisadas e constatou-se que o clima e o local do meio urbano interferiram principalmente nas fenofases floração e frutificação das espécies estudadas. Tabebuia chrysotricha floresceu de julho a outubro enquanto seu período para ocorrência natural é de agosto a setembro. Notou-se também, que em ambas as espécies, esta mesma fenofase não ocorreu em todos os indivíduos. Quanto à frutificação, constatou-se que esta, foi de baixa intensidade, possivelmente em decorrência do baixo número de polinizadores em ambientes urbanos. 
ALMEIDA, E. M.; ALVES, M. A. S. Fenologia de Psychotria nuda e P. brasiliensis (Rubiaceae) em uma área de Floresta Atlântica no sudeste do Brasil. Acta Botanica Brasilica, v.14, n. 3, p. 335-346, 2000.

AMORIM, I. L.; SAMPAIO, E. V. S. B.; ARAÚJO, E. Fenologia de espécies lenhosas da caatinga do Seridó, RN. Revista Árvore, v. 33, p. 491-499, 2009.

BArroso, G. M., CostA, C. G., ICHASO, C. L. F., GUIMARÃES, E. F.; LiMA, H. C. Sistemática de Angiospermas do Brasil. Viçosa: Impr. Univ., v. 3, 1991. 326 p.

BATALHA, M. A.; MARTINS, F. R. Floristic, frequency, and vegetation life-form spectra of a cerrado site.Brazilian Journal of Biology., v.64, n.2, p.201-209, 2004.

BATALHA, M. A.; MANTOVANI, W. Reproductive phenological patterns of cerrado plant species at the Pé-deGigante Reserve (Santa Rita do Passa Quatro, SP, Brazil): a comparison between the herbaceous and woody floras. Revista Brasileira de Biologia, v.60, n.1, p.129-145, 2000.

BAZA-MENDONÇA, L.; ANJOS, L. dos. Beija-flores (Aves, Trochilidae) e seus recursos florais em uma área urbana do Sul do Brasil. Revista Brasileira de Zoologia, v. 22, n. 1, p. 51-59, 2005.

BRUN, F. G. K.; LONGHI, S. J. ; BRUN, E. J.; FREITAG, A. S. ; SCHUMACHER, M. V. Comportamento fenológico e efeito da poda em algumas espécies empregadas na arborização do bairro Camobi - Santa Maria, RS. Revista da Sociedade Brasileira de Arborização Urbana, v. 2, n. 1, p. 44-63, 2007.

CARVALHO, P. E. R. Espécies florestais brasileiras. Recomendações silvicullturais, potencialidades e uso da madeira. Colombo: Embrapa-CNPF, 1994. 674p.

CARVAlHO, P. E. R. Espécies Arbóreas Brasileiras. v. 1. Brasília: Embrapa Informação Tecnológica, $2006 a$. $1039 \mathrm{p}$.

CARVAlHO, P. E. R. Espécies Arbóreas Brasileiras. v. 2. Brasília: Embrapa Informação Tecnológica, 2006 b. 627 p.

COELHO, A.; MACHADO, C. G. Fenologia reprodutiva de Prepusa montana Mart. (Gentianaceae) em uma área de campo rupestre da Chapada Diamantina, BA, Brasil. Revista brasileira de Botânica, v. 32, n. 2, p. 405-410, 2009.

CORLETT, R. T. Reproductive phenology of Hong Kong shrubland. Journal of Tropical Ecology, v. 9, n . 4, v. 501-510, 1993.

FERRAZ, D. K.; ARTES, R.; MANTOVANI, W.; MAGALHÃES, L. M. Fenologia de árvores em fragmento de mata em São Paulo, SP. Brazilian Journal of Biology, v. 59, n. 2, p. 305-317, 1999.

FENOLOGIA DE DUAS ESPÉCIES DE IPÊ... 
FOURNIER, L. A. Un método cuantitativo para lamedición de características fenológicas en árboles. Turrialba, v. 24, p. 422-423, 1974.

FOURNIER, L. A.; CHARPANTIER, C. O. El tamaño da amostra y la frecuencia de las observaciones en el estudio de las característica fenologicas de los árboles tropicales. Turrialba, v. 25, p. 45-48, 1975.

FRANKIE, G. W., BAKER, H. G.; OPLER, P. A. Comparative phenological studies of trees in tropical lowland wet and dry forest sites of Costa Rica. Journal of Ecology, v. 62, p. 881-913, 1974.

GUILHERME, F. A. G.; SAlGADO, A. A.; COSTA, E. A.; ZORTÉA, M. Fenologia de Cybistax antisyphilitica (Mart.) Mart. (Bignoniaceae) na região urbana de Jataí, Goiás. Bioscience Journal, v. 27, n. 1, p. 138-147, 2011.

INDEX KEWENSIS. 2010. The Internacional Plan Names Index. Disponível em: $<$ http://www.ipni.org/ipni/plantnamesearchpage.do>. Acesso em: 02/02/2010.

KAGEYAMA, P. Y.; GANDARA, F. B.; OLIVEIRA, R. E.; MORAES, L. F. D. Restauração da Mata Ciliar: manual para recuperação de áreas ciliares e microbaciais. Piracicaba: SEMADS, 2001. 104 p.

LENZI, M. ORTH, I. A. Fenologia Reprodutiva, morfologia floral de Shinus terebinthifoluis Raddi (Anacardiácea) em restinga da Ilha de Santa Catarina, Brasil. Biotemas, v. 17, n. 2, p. 67-89, 2004.

LONGHI, S. J. Fenologia de algumas espécies florestais e ornamentais. Revista Centro de Ciências Rurais, v. 14, n. 3-4, p. 231-240, 1984.

LORENZI, H. Árvores brasileiras: manual de identificação e cultivo de plantas arbóreas nativas do Brasil. Vol. 1, $3^{\mathrm{a}}$ Ed. Nova Odessa, SP: Instituto Plantarum, 2002. 352 p.

LORENZI, H.; SOUZA, H. Plantas Ornamentais no Brasil: Arbustivas, herbáceas e trepadeiras. São Paulo: Nova Odessa, 2001. 1120 p.

MAGINI, C.; CHAGAS, R. L. Microzoneamento e diagnóstico físico-químico do Ribeirão das Araras, Araras-SP. Geociências, v. 22, n. 2, p. 195-208, 2003.

MARQUES, M. C. M.; OLIVEIRA, P. E. A. M. Fenologia de espécies do dossel e do sub-bosque de duas Florestas de Restingas na Ilha do Mel, sul do Brasil. Revista Brasileira de Botânica, v. 27, n. 4, p. 713-723, 2004.

MARTINI, A; BIONDI, D; BATISTA, A. C. Fenologia de Tabebuia chrysotricha (Ipê-Amarelo) no ambiente urbano de Curitiba (PR). Revista da Sociedade Brasileira de Arborização Urbana, v. 6, n. 4, p. 51-67, 2011.

MENDONÇA, R. C.; FElfili, J. M.; WAlTER, B. M. T.; SilvA-JUNIOR, M. C.; REZENDE, A. V.; FILGUEIRAS, T. S.; NOGUEIRA, P.E. Flora Vascular do Cerrado. In: SANO, S. M.; ALMEIDA, P.A. (Eds.). Cerrado: Ambiente e Flora. Planaltina: EMBRAPA - Cerrados, 1998. p. 289-556.

MORELlATO, L. P. C.; RODRIGUES, R. R.; LEITÃO FILHO, H. F.; JOLY, C. A. Estudo comparativo da fenologia de espécies arbóreas de floresta de altitude e floresta mesófila semi-decídua na Serra do Japi, Jundiaí, São Paulo. Revista Brasileira de Botânica, v. 12, n. 2, p. 85-98, 1989.

Daniele Rebelatto et al.. 
MORELLATO, L. P. C. Estratégias fenológicas de espécies arbóreas em floresta de altitude na Serra do Japi, Jundiaí, São Paulo. Brazilian Journal of Biology, v. 50, n. 1, p. 149-162, 1990.

MORELATTO, L. P. C.; LEITÃO-FILHO, H. F. Estratégias fenológicas de espécies arbóreas em floresta mesófila na Serra do Japi, Jundiaí-SP. Brazilian Journal of Biology, v. 50, n. 3, p. 163-173, 1990.

MORELlATO, L. P. C. Sazonalidade e dinâmica de ecossistemas florestais na Serra do Japi. In: MORELLATO, L. P. C. (Ed.). História natural da Serra do Japi: ecologia e preservação de uma área florestal no Sudeste do Brasil. Campinas: Universidade Estadual de Campinas/Fundação de Amparo à Pesquisa do Estado de São Paulo, 1992. p. 98-110.

MORELATTO, L. P. C.; LEITÃO-FILHO, H. F. Reproductive phenology of climbers in Southeastern Brazilian Forest, Biotropica, v. 28, n. 2, p. 180-191, 1996.

MORELlATO, L. P. C.; TALORA, D. C.; TAKAHASI, A.; BENKLE, C. C.; ROMERA, E. C.; ZIPPARRO, W. B. Phenology of Atlantic Rain Forest trees: a comparative study. Biotropica, v. 32, n. 3, p. 811-823. 2000.

MORI, S. A.; SILVA, L. A. M.; LISBOA, G.; CORADIN, L. Manual de manejo do herbário fanerogâmico. Ilhéus: Centro de Pesquisa do Cacau, 1989. 34p.

OLIVEIRA, P. E. Fenologia e biologia reprodutiva das espécies de Cerrado. In: SANO, S. M.; ALMEIDA, P.A. (Eds.). Cerrado: ambiente e flora. Planaltina: EMBRAPA - Cerrados, 2008. p.169-188.

PALIOTO, G. F.; SUGIOKA, D. K.; CODA, J.; ZAMPAR, R.; LAZARIN, M. de O.; LOYOLA, M. B. P.; RUBINFILHO, C. J. Fenologia de Espécies Arbóreas no Campus da Universidade Estadual de Maringá. Revista Brasileira de Biociências, v. 5, n. 1, p. 441-443, 2007.

PEREIRA, S.G.; AMARAL, A.F. Fenologia das espécies arbóreas do Bosque do Mocambo, em Patos de Minas MG. Perquirēere - Revista Eletrônica da Pesquisa, v. 5, n. 5, p. 12-25, 2008.

POTASCHEFF, C. M.; MORELlATO, L. P. C. Análise dos Padrões Fenológicos de Populações Vegetais Encontradas no Campus da Unesp - Rio Claro, SP e sua Relação com Variáveis Climáticas. Anais... VIII Congresso de Ecologia do Brasil, 23 a 28 de Setembro de 2007, Caxambu - MG. Disponível em: <http://www.sebecologia.org.br/viiiceb/pdf/723.pdf> Acesso em: 27 ago 2010.

RIVERA, G.; BORCHERT, R. Induction of flowering in tropical trees by a 30-min reduction in photoperiod: evidence from field observations and herbarium collections. Tree Physiology, v. 21, n. 1, p. 201-212. 2000.

RODRIGUES, R. R.; SHEPHERD, G. J. Fatores condicionantes da vegetação ciliar. In: R. R. RODRIGUES; H. F. LEITÃO-FILHO, (Eds.), Matas ciliares: conservação e recuperação. Edusp/Fapesp, São Paulo, 2000. p. 101-107.

ROSSATO, D. R. 2008. Padrões anatômicos, fenológicos, fotossintéticos e de crescimento em espécies arbóreas do cerrado sensu stricto e de mata de galeria. 89 f. Dissertação (Mestrado) - Universidade de Brasília.

FENOLOGIA DE DUAS ESPÉCIES DE IPÊ... 
SANTOS, D. L.; TAKAKI, M. Fenologia de Cedrela fissilis Vell. (Meliaceae) na região rural de Itirapina, SP, Brasil. Acta Botanica Brasilica, v. 19, n. 4, p. 625-632, 2005.

SCHAIK, C. P. V.; TERBORGH, J. W.; WRIGHT, S. J. The phenology of tropical forest: adaptative significance and consequences of consumers. Annual Review of Ecology and Systematics, v. 24, n. 3, p. 353-377, 1993.

SILVÉRIO, D. V.; LENZA, E. Fenologia de espécies lenhosas em um cerrado típico no Parque Municipal do Bacaba, Nova Xavantina, Mato Grosso, Brasil, Biota Neotrópica, v. 10, n. 3, p. 205-216, 2010.

SOUZA, V. C.; LORENZI, H. Botânica Sistemática: Guia ilustrado para identificação das famílias de Fanerógamas nativas e exóticas no Brasil, baseado em APG II. 2a ed. Nova Odessa: Instituto Plantarum, 2008. 704 p.

WILliamS-LINERA, G.; MEAVE, J. A. Patrones fenológicos de bosque lluvioso neotropical de bajura. In: GUARIGUATA, M.; KATTAN, G. (Eds.). Ecología de bosques lluviosos Neotropicales. San Jose: IICA, 2002. p. 407-431. 